\title{
OPEN Retraction Note: Oscillations of the baseline of solar magnetic field and solar irradiance on a millennial timescale
}

\begin{abstract}
V. V. Zharkova, S. J. Shepherd, S. I. Zharkov \& E. Popova
Retraction of: Scientific Reports https://doi.org/10.1038/s41598-019-45584-3, published online 24 June 2019

The Editors have retracted this Article.

After publication, concerns were raised regarding the interpretation of how the Earth-Sun distance changes over time and that some of the assumptions on which analyses presented in the Article are based are incorrect.

The analyses presented in the section entitled "Effects of SIM on a temperature in the terrestrial hemispheres" are based on the assumption that the orbits of the Earth and the Sun about the Solar System barycenter are uncorrelated, so that the Earth-Sun distance changes by an amount comparable to the Sun-barycenter distance. Post-publication peer review has shown that this assumption is inaccurate because the motions of the Earth and the Sun are primarily due to Jupiter and the other giant planets, which accelerate the Earth and the Sun in nearly the same direction, and thereby generate highly-correlated motions in the Earth and Sun. Current ephemeris calculations [1,2] show that the Earth-Sun distance varies over a timescale of a few centuries by substantially less than the amount reported in this article. As a result the Editors no longer have confidence in the conclusions presented.
\end{abstract}

S. I. Zharkov agrees with the retraction. V. V. Zharkova, E. Popova, and S. J. Shepherd disagree with the retraction.

\section{References}

1. Folkner, W. M., Williams, J. G., Boggs, D. H., Park, R.S. \& Kuchynka, P. The Planetary and Lunar Ephemerides DE430 and DE431. The Interplanetary Network Progress Report, Volume 42-196, February 15, 2014.

2. JPL Horizons on-line solar system data, https://ssd.jpl.nasa.gov/?horizons.

(c) (i) Open Access This article is licensed under a Creative Commons Attribution 4.0 International License, which permits use, sharing, adaptation, distribution and reproduction in any medium or format, as long as you give appropriate credit to the original author(s) and the source, provide a link to the Creative Commons license, and indicate if changes were made. The images or other third party material in this article are included in the article's Creative Commons license, unless indicated otherwise in a credit line to the material. If material is not included in the article's Creative Commons license and your intended use is not permitted by statutory regulation or exceeds the permitted use, you will need to obtain permission directly from the copyright holder. To view a copy of this license, visit http://creativecommons.org/licenses/by/4.0/.

(c) The Publisher 2020 